\title{
Development of Monitoring and Diagnostic Methods for Robots Used in Remediation of Waste Sites 1999 Technical Progress Report
}

\author{
Project Number 60040 \\ Grant Number DE-FG07-97-ER14830 \\ Principal Investigator: Michael Martin, Foster-Miller Technologies, Inc. \\ Project Directors: Dr. Robert E. Price and Chester E. Miller
}

The final assembly of the test rig was completed in January 1999 (see Figure 1). The test rig incorporated a wheel motor typical of those used for hydraulic robots, and allowed wheel motor loading at expected operating conditions. The rig included instrumentation, as shown in Figure 2, for acquisition of key parameters for both unfaulted baseline and inserted fault runs.

Checkout of the test rig was accomplished in two phases. In the first phase, only the wheel motor was connected to the hydraulic supply and the driven pump disconnected. With the rig in this configuration, operation of the wheel motor control loop and the monitoring and diagnostic (M\&D) data acquisition system was verified. In the second phase, the driven pump was connected to the wheel motor and the operation of the rig under load was confirmed and unfaulted baseline data were acquired.

A list of 13 faults was developed (see Table 1). All faults were inserted and data were acquired. The data files were electronically transmitted to Rice University for analysis using Analytical Redundancy (AR), a model-based static space technique that derives the maximum number of independent tests of the consistency of sensor data with the linearized system model and past sensor and control inputs.

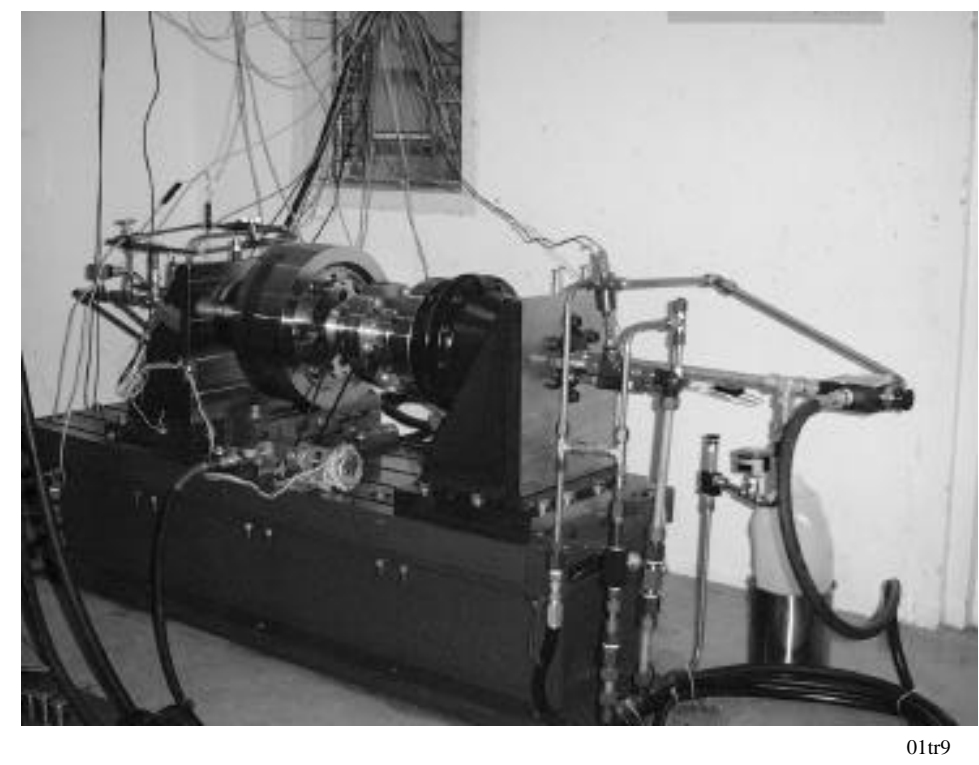

Figure 1. Test Rig Assembly 


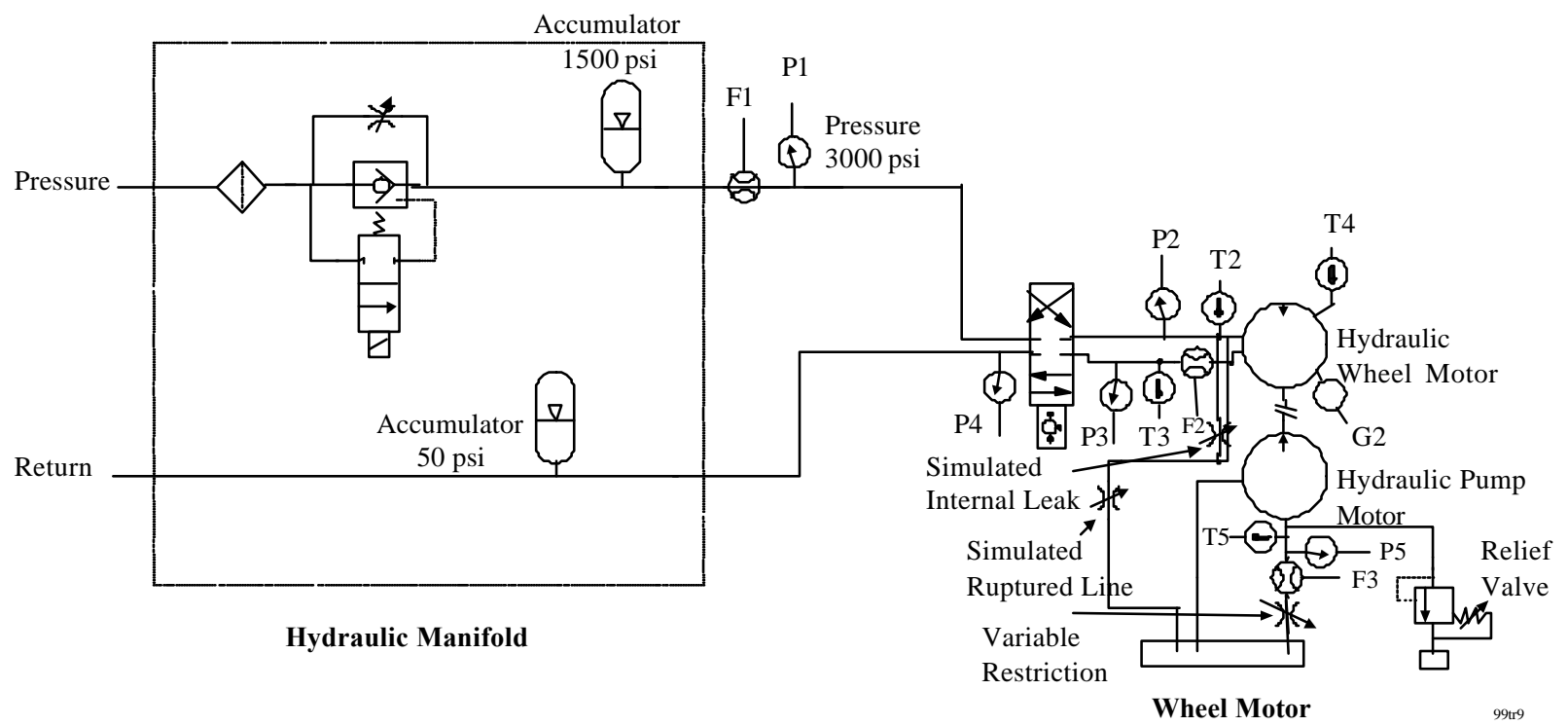

\begin{tabular}{|ll|ll|}
\hline \multicolumn{3}{|c|}{ Sensor Measurement Ranges } \\
\hline $\mathrm{P} 1-\mathrm{P} 3$ & 0 to $3000 \mathrm{psi}$ to $100 \mathrm{~Hz}$ & $\mathrm{~F} 1-\mathrm{F} 3$ & 0 to $10 \mathrm{gpm}$ turbine flow meter \\
$\mathrm{P} 4$ & 0 to $100 \mathrm{psi}$ to $100 \mathrm{~Hz}$ & I1 $-\mathrm{I} 3$ & 0 to $50 \mathrm{~A}, 3$-phase ac current* \\
$\mathrm{P} 5$ & 0 to 5000 psi to $100 \mathrm{~Hz}$ & $\mathrm{~L} 1$ & 0 to 2 in. liquid level* \\
T1 - T5 & K-type thermocouples $\left(60^{\circ} \mathrm{F} \text { to } 200^{\circ} \mathrm{F}\right)^{*}$ & K1 & ac power, 0 to $50 \mathrm{~kW}$ (not shown) \\
G1 - G2 & 0 to $1 \mathrm{~g}$ acceleration $(100 \mathrm{~Hz})^{*}$ & & \\
\hline
\end{tabular}

*Sensors T1, G1, I1 - I3, and L1 are not shown on the test rig diagram as these sensors were included on the HPSS.

Figure 2. Test Rig Hydraulic Schematic 
Table 1. Implanted Faults

\begin{tabular}{|c|c|c|c|}
\hline $\begin{array}{l}\text { Fault No. and } \\
\text { Component }\end{array}$ & Fault & Method of Detection & Method of Installation \\
\hline \multicolumn{4}{|c|}{ Hydraulic Power Supply System (HPSS) } \\
\hline 3. Pump drive motor (ac) & Motor fault; open winding & Case vibration and motor current & Remove fuse from one ac phase \\
\hline 4. Cooling fan & $\begin{array}{l}\text { Loss of oil cooling; open } \\
\text { winding (Rosie fault) }\end{array}$ & $\begin{array}{l}\text { Pump motor and fluid temperature } \\
\text { increases }\end{array}$ & Shut off cooling water flow \\
\hline 5. Hydraulic pump & Scored housing & $\begin{array}{l}\text { Low output pressure/flow, } \\
\text { vibration }\end{array}$ & Use existing damaged pump \\
\hline \multicolumn{4}{|l|}{ Wheel Motor } \\
\hline 8. Hydraulic motor & Loss of casing oil & Vibration & Bleed casing oil \\
\hline 9. Control valve & Open winding & Change in delta $\mathrm{P}$ or flow & Relay-controlled line break \\
\hline 10. Control valve & Sticking valve & Change in delta $\mathrm{P}$ or flow & $\begin{array}{l}\text { Change control profile in } \\
\text { software }\end{array}$ \\
\hline 11 Hydraulic motor & Ruptured supply line & Tank level change & Tee flow to separate tank \\
\hline 12. Resolver & Broken belt or damaged resolver & Loss of speed control & Relay-controlled line break \\
\hline
\end{tabular}

